\title{
Chapter 15 \\ The Contribution of Self-Help Groups to the Mental Health/Substance Use Services System
}

\author{
Thomas J. Powell and Brian E. Perron
}

\begin{abstract}
Self-help groups provide an immense amount of service, which mental health professionals do not adequately understand or coordinate with their services. Epidemiological surveys have documented the profiles of self-help users, the amount of self-help use, and the association between self-help use and professional services. The large majority of self-help users use professional services sometimes as a gateway into professional services, other times concurrently with professional service or as aftercare following a course of professional services. The hallmark features of self-help groups: their use of the experiential perspective, referent power, and reciprocal helping relationships are contrasted with professional mental health services. The essential elements of effective referrals to self-help groups are discussed. At another level, the chapter also discusses the organizational supports necessary for effective collaboration between self-help groups and professional services. While the boundaries between mental health services and self-help groups must be respected, both parties have much to gain by entering into more extensive community partnerships.
\end{abstract}

Self-help groups are responsible for an immense amount of service to the larger $\mathrm{M} / \mathrm{SU}^{1}$ system. Nonetheless, this contribution tends to be underestimated and its experiential nature poorly understood. Self-help services are complementary to professional services, and yet professionals often do not coordinate with them. Moreover, the reluctance of professionals to support self-help groups in the community is part of the reason the contribution of self-help groups is not fully realized (Salzer, Rappaport, \& Segre, 1999). To help address these problems, this chapter (1) Documents the volume and demographics of self-help utilization including the racial/ethnic characteristics of the participants using epidemiologic

T.J. Powell $(\otimes)$

School of Social Work, University of Michigan, Ann Arbor, MI, USA

e-mail: tpowell@umich.edu

${ }^{1} \mathrm{M} / \mathrm{SU}$ refers to "mental and/or substance use" following the practice of the: Committee on Crossing the Quality Chasm: Adaptation to Mental Health and Addictive Disorders (2006). Improving the quality of health care for mental and substance-use conditions: Quality chasm series. Washington, D.C.: Institute of Medicine, National Academies Press. 
data; (2) Describes the nature of self-help in terms of its experiential perspective, distinctive base of power, and the reciprocal nature of its helping relationships; (3) Highlights challenges associated with and provide recommendations for coordinating self-help and professional services; (4) Addresses the potential of the $\mathrm{M} / \mathrm{SU}$ services system to enhance the acceptance and growth of the self-help sector by engaging self-help groups in organizational exchanges and in collaborative community projects.

\subsection{Service Utilization}

\subsubsection{Volume}

In comparison with the mental health/addictive specialty sector of the M/SU system, self-help groups provide services to fewer people. Of the $13 \%$ using outpatient services in a 12-month period, $5.8 \%$ accessed the mental/addictive sector while $3.2 \%$ accessed unspecified groups in the self-help sector (Kessler et al., 1999). Although the proportion served by the self-help sector is large by any measure, the professional mental health/addictive specialty sector serves more people than the self-help sector. However, if the measure is visits and not people, the ranks are reversed. Forty percent of all outpatient visits for psychiatric problems are to self-help groups according to the National Comorbidity Survey (NCS) (Kessler et al., 1999). The $40 \%$ to self-help compares to $35 \%$ to the mental health/addictive specialty sector, $16 \%$ to the human services sector, and $8 \%$ to the general medical sector (Kessler, Mickelson, \& Zhao, 1997).

Additional details are available from a later national survey. The Midlife Development in the United States (MIDUS) survey is based on interviews conducted in 1995-1996 following the 1990-1992 NCS interviews. More than one-third of the MIDUS self-help attendees were in groups for substance use problems, accounting for nearly $70 \%$ of the self-help visits. People with substance use problems are more likely to go to self-help groups, attend more frequently, and attend for longer periods than those with other mental health problems. Participants in substance use self-help groups average 76 visits a year while those in other self-help groups such as NAMI, Recovery, Inc. and DBSA (Depression and Bipolar Support Alliance) average 24 visits. Fifty percent of those attending substance use groups, mostly 12-step groups, also participate in professional treatment services. The proportion using professional services among non-substance use groups is even higher at $75 \%$ (Kessler et al., 1997).

\subsubsection{Demographics}

The MIDUS survey provides information about the age, income, gender, and marital status of self-help participants. Younger people participate more than older people. 
However, the participation of all age groups has continued to increase since WWII. Assuming a continuation of the trend, the 1996 figure of $18 \%$ of the population using self-help services over the life course has already been eclipsed. Participation also varies by income - it is inversely related to income, especially for those with substance use problems (Kessler et al., 1997).

Women participate in self-help groups more often than men. Even in substance use groups such as AA or NA, which are sometimes thought of as male preserves, women participate more often in proportion to their level of substance use problems. Unmarried adults and those with less supportive networks also participate more often in self-help according to the MIDUS survey.

The MIDUS survey is the source of some finely nuanced findings about race: "Blacks are only half as likely as Whites to participate in self-help groups overall, but this difference is largely due to an extremely low rate of participation in groups for people with eating problems. There are no significant race differences in participation in groups for substance use problems or emotional problems" (Kessler et al., 1997, p. 33). This is consistent with a treatment follow-up study by Humphreys and colleagues $(1991,1994)$. They found that African Americans were at least as likely to attend and benefit from 12-step groups as Whites. These findings, which some might think run counter to conventional wisdom, might be more easily assimilated if it is understood that African Americans have a lower prevalence rate for substance use problems than Whites.

The National Epidemiologic Survey on Alcohol and Related Conditions (NESARC) interviews 2001-2002 is a more recent source of information about Black participation in 12-step groups. Examining those with drug use disorders (DUDs), the findings suggest that African Americans participate in 12-step groups at a higher level than Whites. The participation pattern for Latinos is lower than that for Blacks and similar to that of Whites (Perron, Mowbray, Glass, Delva, Vaughn, \& Howard, 2009). However, the use of self-help services should be considered in relation to the total treatment package. For example, the NESARC data suggests that Blacks tend to use private practitioners (physicians, social workers, psychiatrists, and other professionals) less than other racial and ethnic groups, though they are somewhat more frequent users of outpatient and drug rehabilitation services. However, this finding needs to be considered in the context that other studies suggest that 12-step groups may be more effective than professional services (Humphreys \& Moos, 2007; Seligman, 1995). Therefore, a preference for 12-step involvement may be wise. But not to be lost sight of, other studies have found that the combination of 12-step participation and professional treatment is best (Fiorentine \& Hillhouse, 2000; McLellan, 2008)

Still there is much about these rates that need clarification and it is best to think of these figures as rough estimates. One puzzling piece of information is that the Alcoholics Anonymous Membership Survey (2007) shows much lower rates of Black and Hispanic participation than one would expect from the national surveys. Delving into this issue is beyond this paper but worthy of examination.

Aside from the rates of relative participation, the more significant meta-finding is that both minorities and non-minorities are under-enrolled in self-help groups 
and under-treated in professional services. Using the MIDUS data set, Wang and colleagues (2000) found under-treatment in that even among persons with severe mental illness, only $25 \%$ were receiving guideline-concordant, evidencebased treatment. Using the more recent (2001-2003) National Comorbidity Survey Replication (NCS-R), Wang et al. (2005) found under-enrollment in that the people with substance use and impulse control disorders were least likely to connect with treatment. Based on NESARC data, less than $15 \%$ of those with alcohol use disorder receive treatment, whether self-help or professional in nature (Cohen, Feinn, Arias, \& Kranzler, 2007). For mental and substance use problems as a whole, only a fraction of those who could presumably benefit from self-help services actually receive them (Kessler et al., 1997). Based on the NCS-R data, the authors conclude, "Unmet need for treatment is greatest in traditionally underserved groups, including elderly persons, racial-ethnic minorities, those with low incomes, those without insurance, and residents of rural areas" (Wang et al., 2005, p. 629). For other serious mental disorders, as well as substance use disorders, concurrent participation in self-help groups and professional treatment can be a way to address this unmet need. Considerable support exists for combining professional treatment and selfhelp services for serious mental illness as well as substance use (Davidson et al., 1999; Freimuth, 2000; Humphreys et al., 2004; Magura, 2007; Magura, Laudet, Mahmood, Rosenblum, \& Knight, 2002; McLellan, 2008; Moos \& Timko, 2008; Pistrang, Barker, \& Humphreys, 2008; Powell, 1990; Powell, Yeaton, Hill, \& Silk, 2001).

\subsubsection{Financial Implications}

The question of whether self-help services can offset costly professional services is probably premature given the prevailing under-treatment of severe mental illness. Since people with mental illness struggle with too widely spaced and time-pressured medication reviews, scarce supportive housing, work, and education services, and limited access to wraparound services such as ACT, it is hardly surprising that selfhelp groups seek more of these services for their members (Wang et al., 2005). As long as professional services are weak and lack appropriate intensity, initiatives to substitute self-help services for professional services should be considered potentially counterproductive. Yet, it should be acknowledged that there are already areas where substitution is less concerning. In the area of substance use disorders, Humphreys \& Moos (2007) found that participation in 12-step groups improved post-treatment outcomes while it also reduced the cost of continuing professional care.

But narrow cost-effectiveness considerations shouldn't be the only concern. Cost-benefit analyses are needed to estimate the costs of lost workforce productivity and losses of disability-adjusted life years (DALYS) associated with M/SU disorders. M/SU disorders are high on the list of all diseases and injuries contributing to DALYS (USPHS, 2000; WHO, 2001). The huge costs of DALYS compared to the minimal costs of self-help services suggest a very favorable cost-benefit 
ratio - assuming of course some level of self-help effectiveness. With regard to cost, it should also be considered that self-help use produces more self-help resources. More use generates more pairs of givers and receivers, more personal models, more recovery stories, and more resource networks. To raise awareness of this multiplier effect, Riessman (1995) referred to prosumers rather than consumers of self-help services.

\subsubsection{The Timing of Self-Help and Professional Services}

Concurrent participation in self-help and professional treatment is only one of several ways self-help and professional services relate to one another (Meissen, Wituk, Warren \& Shepherd 2000). Self-help participation may take place before, during, and after professional treatment. And of course it can take place independent of any connection to professional treatment. When it comes before professional treatment it can serve as a mechanism that informs, motivates, reduces barriers, and provides encouragement to engage professional services. Self-help participation may also reconnect participants who earlier were dissatisfied with professional services, or for a variety of reasons experienced a disruption in treatment. Self-help groups also facilitate access to professional services since they tend to be a source of reliable information about who the best providers are and how to access them (Warner et al., 1994). Informal conversations about the benefits of professional treatment tend to enhance motivation. Barriers may be reduced as self-help peers locate possible sources of funding for professional services and assist with everyday problems related to transportation and child care. Considering the prominence of professional services on the agenda of self-help groups and the frequency with which it is a topic of side conversations, it would seem likely that self-help participation encourages participation in professional treatment (Aron, Honberg \& Duckworth et al. 2009). But of course it could have the opposite effect. Stories about self-help members who discourage the use of professional services are ubiquitous (Chesler, 1990). No doubt discouragement takes place but it needs to be considered against the backdrop that many more self-helpers participate in professional services than the reverse (Kessler et al., 1997). A more specific allegation is that self-help groups discourage taking prescribed medications. No doubt this occurs in contravention to AA policy. However, the extent to which this occurs may be more limited than supposed. A study based on interviews with AA contact persons suggests that they were open to members taking prescribed psychiatric medications (Meissen, Powell, Wituk, Girrens, \& Arteaga, 1999). Yet a single study is not enough and the ongoing debates suggest that it should be a priority area for study. Meanwhile, there are variant 12-step groups, including Dual Recovery Anonymous, that should be considered for persons with co-occurring disorders (Ries, Galanter, \& Tonigan, 2008).

Whether self-help is included in aftercare plans largely depends on professional views about the efficacy of self-help (Salzer, Rappaport, \& Segre, 2001). When the views are strongly positive, self-help may be seen as the main engine of recovery (Moos, 2007). Professionals subscribing to this view seek to prepare clients and 
patients for full and productive participation in the recovering community which might be thought of as loosely made up of the members and friends of 12-step groups (Project MATCH Research Group et al., 1998). However, many professionals see self-help as a second best resource, to be accessed only when professional treatment is not an option (Salzer, Rappaport, \& Segre, 1999). In the worst case scenario, some professionals seem to make so called referrals to self-help groups to detach themselves from unwanted clients (Powell \& Perron, 2010).

A contrasting and appropriate use of self-help is to maintain or amplify the gains of professional treatment and to sustain them over time. This approach would be consistent with an understanding that the nature of the task changes as individuals move from acute to continuing care status or from treatment to rehabilitation services. Simultaneously, they may be moving from a practicing to a recovering person, and from victim to survivor. As individuals move along these continua the balance shifts toward increasing self-help participation as professional care decreases or is stepped down.

Unfortunately, few data are available to document the relative frequency of these patterns. That which is available suggests that participants in self-help are likely to also participate in professional services. This is less true of participants in professional services, as suggested by NCS data: " $63 \%$ of those in self-help were also in some other sector, compared with $42-50 \%$ of those in other sectors" (Kessler et al., 1999, p. 121). It seems that self-help users are more aware of the added value of professional services than those using professional services are aware of the potential additive value of self-help services.

\subsection{Nature of Self-Help}

Self-help is enormously diverse. Some part of this diversity is reflected in their different names: mutual help groups, mutual aid groups, support groups, 12-step groups, and fellowships. But even this list omits the increasingly important online groups (Murray, Burns, See-Tai, Lai, \& Nazareth, 2005) whose special features are discussed in more detail in Chapter 5 of this book. Differences in names, however, do not reference some of the fundamental differences among self-help groups. One example is how they view the origin of the problem. Some assume the problem resides in the individual, e.g., 12-step groups. Other groups assume the problem resides in society's lack of acceptance, e.g., LGBTQ groups. Still others assume that the problem is located in both the individual and society, e.g., NAMI (Sagarin, 1969). The perceived locus of the problem is in turn related to the different positions groups take on advocacy.

Self-help groups also vary on a variety of organizational dimensions. Some selfhelp groups have national and local affiliate structures, e.g., DBSA, Recovery Inc. whereas others operate as unaffiliated local groups. Some have well-defined formats, e.g., 12-step and GROW groups, while others use less structured formats, e.g., NAMI and DBSA (Schubert \& Borkman, 1991). 
And then there are the uses of "self-help" that are different from its use here. Self-help, as used here, is not seeking guidance and inspiration in "self-help" books, which are often written by professionals (Norcross, 2006). Self-help is not the use of self-administered therapies often derived from professional therapies (Watkins \& Clum, 2008). Agencies employing consumers to provide services are not self-help groups as they are understood here (see comments below about reciprocal helping roles) (Hardiman \& Segal, 2003). Nor are cooperative residences that are built on self-help ideas such as the 12 steps (Majer et al., 2008). Most decidedly, self-help is not be confused with pulling oneself up by one's bootstraps. Self-help isn't done alone; it is done in groups and involves mutual help.

Despite the diversity, self-help groups share a basic appeal. People, anxious or in difficulty, share a universal desire to associate with others in similar situation (Schacter, 1959). These associations lead to comparisons and self-appraisals (Brown, 2009; Davison, Pennebaker, \& Dickerson, 2000; Festinger, 1954). These in turn can result in a number of supportive conclusions such as, "I'm not alone; I'm liked in this community of respectable people. In some ways, I'm doing comparatively well and can help others do better. In other respects, I could do better and I can learn from people who will work with me." This is the group context in which mutual aid is exchanged. This mutuality is less typical of professionally facilitated or led support groups (Salem, Reischl \& Randall, 2008; Toro et al., 1988) though professionals often play helpful secondary roles in self-help groups (Gitterman \& Shulman, 2005; Shepherd et al., 1999; Wituk, Shepherd, Slavich, Warren, \& Meissen, 2000). Moreover, this doesn't include the important role professionals play in the formation of self-help groups (Borman, 1979). However, excluding professionally led support groups is consistent with the practice of national epidemiological surveys ( $R$. Kessler et al., 1997) and consistent with a potentially insightful understanding of the "self" in self-help groups. The term self refers to a group of ourselves who share common experiences, challenges, and identities.

Identifying with these shared attributes is the basis of group cohesion and the mutual exchange of help (Mowrer, 1984). Thus a more accurate, though more cumbersome, name might be self-help/mutual help groups. Shedding the cumbersome, self-help groups share three fundamental properties: (a) the experiential perspective, (b) a distinctive form of social power, and (c) a behavioral pattern of giving and receiving help. The experiential perspective highlights the nature of sharing in the self-help group. The basis of power speaks to who is an authority in self-help groups. And giving as well as receiving help refers to a behavioral pattern linked to positive outcomes.

\subsubsection{Experiential Perspective}

Experience is the currency of the realm or the thing that is exchanged in self-help groups. Sharing goes something like: My experience is .... What is your experience? What has worked for you? What has worked for me is .... The process of 
contending with the condition or situation is the basis of the experiential perspective. It differs from the perspective of the professional that is rooted in scholarly, scientific study (Borkman, 1990; Mowrer, 1984).

\subsubsection{Referent Power}

What moves people to action? To whom do we grant the power to move us? Action might be taken because we're rewarded, forced, or persuaded by the logic of the proposed action (French \& Raven, 1959; Raven, Schwarzwald, \& Koslowsky, 1998). We might also be moved by expert power because of the formal educational credentials of the person making the recommendation (Raven, 1988). This is the predominant form of power in professional mental health services. In self-help groups, referent power is the prevailing form of social power (Powell, Hill, Warner, Yeaton, \& Silk, 2000; Salem, Reischl, Gallacher, \& Randall, 2000). Referent power is visible in its effects. By definition, referent power is evident when the focal individual is under the influence of those he or she admires and wants to be like. The individual is moved to change because of his or her desire to be liked and approved by the referent individual or group.

\subsubsection{Reciprocal Giving and Receiving Roles}

In self-help groups, participants help others as well as themselves. In so doing the helper benefits as Riessman $(1995,1965)$ laid out in the helper-therapy principle. It's a case of, for example, the tutor benefiting as much or more than the tutee. Other studies of the principle have shown surprising benefits, e.g., increased longevity (Brown, Nesse, Vinokur, \& Smith, 2003). Obviously, the client of a professional provider should not endeavor to help the provider. Yet help giving as well as help receiving occurs in self-help groups. And research in these groups suggests there are benefits to giving as well as receiving help (Maton, 1988; Roberts et al., 1999). The self-help participant who gives help may begin to see him- or herself as increasingly competent and powerful instead of deficient and helpless. The giver, then, seems to be rewarded with increased self-efficacy.

The foregoing analysis is intended to enable M/SU professionals to recognize authentic self-help and to more effectively relate to its healing properties. In the period leading up to the landmark Surgeon General's Workshop on Self-Help and Public Health (1988) anything labeled self-help was swept up in an attractive social movement. But the period was also marked by the overly inclusive and indiscriminate use of the term self-help. The counter move was to ridicule the self-help movement for harboring trivial groups such as Messies Anonymous. Nonetheless the purifying criticisms combined with the popularity of self-help set the stage for including questions about self-help services in important national epidemiological surveys in the 1990s, the Epidemiological Catchment Area Survey (ECA) (Narrow, 
Regier, Rae, Manderscheid, \& Locke, 1993) and the NCS (Kessler et al., 1999). This inclusion marked self-help's entry into the legitimate mainstream of mental health services. These surveys also revealed self-help groups to be a significant source of help for the U.S. population. Yet much remains to be done to integrate self-help services into the larger M/SU services system while preserving and enhancing their essential autonomy. Progress along these lines will depend on a better understanding of how the properties of self-help differ from those of professional services. It will also depend on developing enlightened professionals who appreciate that self-help is neither a mere adjunct to professional service nor something that is interchangeable with it (White, 1998).

\subsection{Coordinating Professional Services with Self-Help}

The fundamental reason to coordinate professional services with self-help services is to create a service system that takes advantage of the complementary strengths of each approach. Each compensates for elements that are in short supply in the other. The scholarly/scientific perspective of the professional, while long on expert wisdom is relatively short on experiential wisdom. Self-help members, and this means seasoned and successful ones, have potentially a great deal to offer about how to negotiate the practical, everyday issues stirred up by the troubling condition or situation. Examples of these practical concerns can be seen in the following questions: How do you remember to take your medication? What do you do when you don't want to take them? How do you deal with the side effects? How do you explain the gaps in your work history to potential employers? How do you resist the temptations of alcohol or drugs? How do you say no to old buddies? How do you quiet the troubling voices, and control the suspicions that rise and recede in your thoughts? These "how" questions imply a type of anxiety that is especially responsive to the care of those who have been there. And on a different heading, there are questions like the following: What did you have to do to get SSDI (Social Security Disability Insurance) benefits? These questions address completing practical tasks without which there can be little quality in one's life.

Taken together these questions connect with issues that both the self-help and professional sector deal with. The essential idea is that conversations in both sectors about these issues can enrich both modalities. The professional can enrich therapy by asking about prevailing ideas, suggestions, or sources of practical assistance in the self-help group. Proceeding in the reverse direction, the professional can ask the client to solicit the opinions of self-help members on some topic of interest to therapy.

\subsubsection{Referral-Competent Counselors}

Successful referral requires knowledgeable, self-help competent professionals. This competence is not a common outcome of basic education in any of the M/SU professions (Kurtz, 1997). Indeed, given the epidemiologically documented importance 
of self-help groups it is disconcerting that graduates of these professional programs are not better prepared to work with self-help groups (Meissen, Mason, \& Gleason, 1991; White \& Kurtz, 2005). Currently, professionals seeking to acquire self-help competence must do so on a continuing education, self-initiated basis after obtaining their professional degree. To elicit interest in acquiring this competence they might be asked to consider some imaginary or real personal problem. Then they could be asked how they might benefit from both persons who shared their experience and from professional helpers, in other words from those working from an experiential perspective and from those with a scholarly scientific perspective. Professionals might also be asked to reflect on the importance of admired referent individuals in their own lives to appreciate how this power might play out within self-help groups. Finally professionals could be encouraged to contemplate how the dependency associated with client/patient status can be demoralizing. Then they might be asked to consider how transforming oneself from a receiver of help to a giver of help can constitute a self-efficacy preventive intervention against the frequent undermining of confidence associated with extended client status.

\subsubsection{Personal Knowledge of Self-Help}

Successful referral requires first-hand knowledge of self-help groups (Kurtz, 1985). Research shows that personal experience with self-help groups is associated with more effective referral practices (Chinman, Kloos, Maria O'Connell, \& Davidson, 2002; Humphreys, 1999). Thus, questions about personal self-help experience may be useful in applications to health and human service professional education programs, just as there are often questions about personal counseling. The idea, of course, is not simply to know whether applicants have had this experience but rather to encourage reflection about how these experiences might inform their professional work. Just as classroom work without a substantive practicum is not enough to learn how to provide professional services, so too book knowledge without hands-on experience is not enough to learn how to work with the self-help sector. Easy ways to begin acquiring this experience is to invite self-help leaders to agencies, visit selfhelp groups, and develop relationships. All this must be done with respect for group norms, e.g., closed meetings, and in a way that makes one's purpose transparent (Wilson, 1995a).

The term referral is problematic because of its professional connotations. It implies the professional is selective about which clients are referred to self-help groups. Self-help leaders are concerned that professionals should not control entry. Referral, they say, should be universal rather than selective. Every person with an alcohol problem should be encouraged to consider AA; every person with a connection to mental illness should be encouraged to consider NAMI. The professional should not screen out certain individuals but rather let the self-help group and the individual decide about suitability (Wilson, 1995b). Professionals should also be aware that an introduction to a self-help group could be more complicated than many professional referrals. It can be seen as going out of the system to a lesserknown entity. In any event, the encouragement needs to be highly individualized. 
Some clients respond best to a low-key discussion of the self-help group; others will need more intensive encouragement. Encouraging participation or putting people in touch with self-help groups suggests a process that should be considered more complicated and requiring more individualization than a routine professional referral.

Only persons knowledgeable about the target self-help program and acquainted with its leaders are in a position to be truly encouraging. Only they have the knowledge-based confidence to discuss the client's fearful, skeptical, hesitant inclinations. This confidence also enables them to engage the client in a detailed conversation about the client's first experiences with the self-help group. The conversation might begin with the question: What was the meeting like? Were there any turn-offs? e.g., people who appeared too sick (or too well) to be in the group; people from a different socioeconomic group who might be difficult to relate to; people who seemed intent on subverting the program; people who appear to be possible predators, etc.? Yes - every intervention has risks, and they must be managed wisely. Still other questions might orient clients to various aspects of the group: Are there options to be selective with respect to the activities? With respect to how you relate to the other participants? Who are the helpful people? Have you thought about who might be helpful to you? What did you learn? Were you a part of any positive conversations?

These conversations may touch on many of the topics included in the Twelve Step Facilitation, a program to encourage active involvement in 12-step groups (Humphreys, 1997; Nowinski \& Baker, 1992; Ries, Galanter, \& Tonigan, 2008). These and other suggested protocols emphasize the use of available tools: readings, service work, sponsors, and the like (Chappel \& DuPont, 1999). Clearly, discussion of their effective use requires a good deal of specific knowledge on the part of the professional counselor (Ries, Galanter, \& Tonigan, 2008).

\subsubsection{Effective Encouragement Strategies}

The research on referrals (read encouragement) is unambiguous. The strongest and most effective referrals connect the self-help prospect with seasoned, welcoming self-help members. This connection to an experienced trained greeter is best if it occurs before the prospect's first meeting. The connection may be by phone, or in person, and preferably include an offer to accompany the newcomer to his or her first meeting. This approach has been successful with 12-step groups and with mental health groups such as the Depression and Bipolar Support Alliance and 12-step groups (Powell et al., 2000; Timko, Debenedetti, \& Billow, 2006; Timko \& Debenedetti, 2007). The various components of these interventions offer the prospect a personalized, anxiety reducing introduction to the self-help group with the opportunity to debrief after the meeting.

An effective encouragement strategy should also include the option of a companion to accompany the newcomer to meetings at least until he or she feels some degree of comfort. The spirit of this recommendation is captured in the saying that sometimes people need more than a travel agent, a travel companion. AA provides 
this kind of companionship but across self-help groups as a whole, too little of it is available. One possible answer to this need resides in the development of peer specialists in M/SU agencies, training for which is provided by the Depression and Bipolar Support Alliance (2009). They also ask potential trainees about their support group leadership experience. Likewise, participation in self-help groups might logically be included among the potential qualifications for peer specialists. Peer specialist job descriptions could then establish the importance of accompanying consumers in a companionable manner to self-help group meetings.

Efforts to encourage participation should recognize that people in certain categories might find it especially beneficial to participate in a self-help group. The MIDUS survey offers clues to these potential beneficiaries with its finding that the not married and those with lower social support from family participated at higher rates in self-help groups (Kessler et al., 1997). Others may also need special attention. Men are generally reticent about asking for help whether it be medical, counseling, or self-help group assistance (Addis \& Mahalik, 2003). They may require individualized strategies to normalize their help seeking, perhaps citing the opportunity it would provide to help others whether family or self-help members.

\subsubsection{Respecting Boundaries}

While much has been made of the need for closer relations between M/SU professionals and self-help groups, it should be understood that differences and distance must be maintained as well. To make the most of the complementarity between selfhelp and professional services, the integrity and autonomy of both professional and self-help modalities must be maintained. Boundaries must be respected to avoid debasing the distinctive help available from each of the modalities. Often this is framed in threats to the autonomy of self-help groups, but it also applies to the integrity of professional programs. In his insightful and influential work, White (1998) cautions against the tendency to cede professional responsibility to 12-step groups. Professionals must retain responsibility for the treatment component of their own programs. The Minnesota model which encourages 12-step involvement is a good idea but when 12-step group activity substitutes for professional treatment activities, it is a good idea taken too far (Miller, 1994). If fruitful conversations are to take place across helping modality boundaries, they will need to be supported by organizational exchanges between self-help groups and M/SU agencies.

\subsection{Organizational and Community Requisites}

Service providers are not independent actors. They are firmly attached to their organizational and community environments (Hatch \& Cunliffe, 2006; Scott, 2005). If self-help facilitation is to become policy, that is become standard practice or the usual course of action within the professional M/SU service system, the organizational environment must support it. To provide this organizational support, the 
professional M/SU service system must extend its boundaries to engage in a variety of exchanges with self-help groups (Heracleous, 2004; Schmid, 2004). The M/SU agency must transition from thinking of itself as a self-contained and self-sufficient entity to thinking of itself as an open-system organization in constant exchange with its environment (Scott, 2003). It must engage in adaptive exchanges with selfhelp groups at all levels of the organization (Donaldson, 2001; Powell \& Perron, 2010). Starting with the highest level, self-help leaders need to be represented on the agency's board of directors. This would be a good place to discuss the mutual obligations of self-help leaders and mental health professionals. Self-help leaders also need to be involved in staff development and in-service training. Staff must be given the time and training necessary to visit self-help groups and develop relationships with their leaders (Wituk, Tiemeyer, Commer, Warren, \& Meissen, 2003). And here a word needs to be said about going beyond 12-step groups. Because of their numbers, and the extensive literature they have generated, 12-step groups sometimes disproportionately dominate the discussion of self-help. Indeed, it is a limitation not entirely escaped in this chapter. However, there is no scarcity of other highly relevant groups and M/SU agencies should be encouraged to engage them. A recent national survey found that self-help groups and related organizations actually outnumber professional mental health organizations (Goldstrom et al., 2006). Groups affiliated with organizations such as NAMI, the Depression and Bipolar Support Alliance, GROW, and Recovery, Inc. are too little attended to by M/SU agencies.

But it is not enough to engage in adaptive exchanges with self-help groups. M/SU agencies must also partner with self-help groups to enhance their institutional status in the community (Scott, 2001; Wituk, Ealey, Brown, Shepherd, \& Meissen, 2005). Self-help groups can become even more significant resources for M/SU agencies as their institutional standing, i.e., as their level of acceptance and approval increases in the community (Baum, 1996; Meyer \& Rowan, 1977; Meyer, 1986). M/SU agencies can be a part of bringing this about by including self-help groups in various community events such as media interviews, panel discussions, poster displays, video productions, etc. (Wang et al., 2000). To the extent they do so, M/SU agencies are likely to experience an increase in their own institutional standing owing to the public endorsements and positive references they receive from a stronger network of self-help groups.

\subsection{Conclusions}

Self-help groups make an immense though somewhat one-sided contribution to the M/SU professional services system. While 12-step groups make an indispensable contribution, a vast range of non-12-step groups remain underutilized to the detriment of the M/SU services system. A great many local NAMIs, DBSAs, and unaffiliated self-help groups receive too little attention from the professional side of the system. 
To address underutilization, $\mathrm{M} / \mathrm{SU}$ professionals need to understand the distinctive complementary properties of self-help groups. They need to understand the experiential nature of self-help, the referent power underlying the helpful influence of self-help leaders, and the unusual opportunity self-help participation offers to experience the benefits of giving help as well as receiving it. M/SU professionals also need to understand the importance of developing relationships with self-help group leaders. These relationships can be built upon to facilitate clients becoming connected to welcoming self-help leaders. With respect to the counseling enterprise, $\mathrm{M} / \mathrm{SU}$ professionals must learn to create opportunities for synergistic dialogues across professional and self-help boundaries.

To sustain these initiatives, organizational support must be in place. Accordingly, $\mathrm{M} / \mathrm{SU}$ agencies must enter into organizational exchanges with self-help groups, all the while being careful to maintain and enhance their integrity and autonomy. Simultaneously, M/SU agencies must partner with self-help groups to enhance their institutional standing and acceptance in the community. In undertaking these actions, M/SU agencies can ensure that more people will participate in self-help groups and that they will be able to choose from a wider range of 12-step and non-12-step groups.

\section{References}

Addis, M. E., \& Mahalik, J. R. (2003). Men, masculinity, and the contexts of help seeking. American Psychologist, 58, 5-14.

Alcoholics Anonymous. Alcoholics Anonymous membership survey 2007. Retrieved February 7, 2009 http://www.aa.org/pdf/products/p-48_07survey.pdf

Aron, L., Honberg, R., \& Duckworth, K. et al. (2009). Grading the States 2009: A report on America's health care system for adults with serious mental illness. Arlington, VA: National Alliance on Mental Illness.

Baum, J. A. C. (1996). Organizational ecology. In S. P. Clegg, C. Hardy \& W. Nord (Eds.), Handbook of organization studies (pp. 77-114). London/Thousand Oaks, CA: Sage.

Borkman, T. J. (1990). Experiential, professional, and lay frames of reference. In T. J. Powell (Ed.), Working with self-help (pp. 3-30). Silver Spring, MD: National Association of Social Workers.

Borman, L. D. (1979). Characteristics of development and growth. In M. A. Lieberman, \& L. D. Borman (Eds.), Self-help groups for coping with crisis (pp. 13-42). San Francisco: Jossey Bass.

Brown, L. D. (2009). Making it sane: Using narrative to explore theory in a mental health consumer-run organization. Qualitative Health Research, 19(2), 243-257.

Brown, S. L., Nesse, R. M., Vinokur, A. D., \& Smith, D. M. (2003). Providing social support may be more beneficial than receiving it: Results from a prospective study of mortality. Psychological Science, 14(3), 320-328.

Chappel, J. N., \& DuPont, R. L. (1999). Twelve-step and mutual-help programs for addictive disorders. The Psychiatric Clinics of North America, 22(2), 425-446.

Chesler, M. A. (1990). The "dangers" of self-help groups. In T. J. Powell (Ed.), Working with self-help (pp. 301-324). Silver Spring, MD: National Association of Social Workers.

Chinman, M. J., Kloos, B. O., Maria O'Connell, M., \& Davidson, L. (2002). Service providers views of psychiatric mutual support groups. Journal of Community Psychology, 30, 349-366.

Cohen, E., Feinn, R., Arias, A., \& Kranzler, H. R. (2007). Alcohol treatment utilization: Findings from the national epidemiologic survey on alcohol and related conditions. Drug \& Alcohol Dependence, 86(2-3), 214-221. 
Committee on Crossing the Quality Chasm: Adaptation to Mental Health and Addictive Disorders. (2006). Improving the quality of health care for mental and substance-use conditions: Quality chasm series. Washington, D.C.: Institute of Medicine, National Academies.

Davidson, L., Chinman, M., Kloos, B., Weingarten, R., Stayner, D., \& Tebes, J. K. (1999). Peer support among individuals with severe mental illness: A review of the evidence. Clinical Psychology-Science \& Practice, 6(2), 165-187.

Davison, K. P., Pennebaker, J. W., \& Dickerson, S. S. (2000). Who talks? the social psychology of illness support groups: The human asset. American Psychologist, 55(2), 205-217.

Department of Health and Human Services Public Health Service. (1988). Surgeon general's workshop on self-help and public health. Health resources and services administration, Bureau of maternal and child health and resource development, Publication no. 224-250. Washington DC.: U. S. Government Printing Office.

Depression and Bipolar Support Alliance (DBSA). Peer specialist training. Retrieved 2/13/2009 http://www.dbsalliance.org/site/PageServer?pagename=training_certified_peer_specialist

Donaldson, L. (2001). The contingency theory of organizations. Thousand Oaks, CA: Sage.

Festinger, L. (1954). A theory of social comparison processes. Human Relations, 7, 117-140.

Fiorentine, R., \& Hillhouse, M. P. (2000). Drug treatment and 12-step program participation: The additive effects of integrated recovery activities. Journal of Substance Abuse Treatment, 18(1), 65-74.

Freimuth, M. (2000). Integrating group psychotherapy and 12-step work: A collaborative approach. International Journal of Group Psychotherapy, 50(3), 297.

French, J. R. P., \& Raven, B. (1959). The bases of social power. In D. Cartwright (Ed.), Studies in social power (pp. 150-167). Ann Arbor, MI: Institute for Social Research, University of Michigan.

Gitterman, A., \& Shulman, L. (2005). Mutual aid groups, vulnerable and resilient populations, and the life cycle. New York: Columbia University Press.

Goldstrom, I. D., Campbell, J., Rogers, J. A., Lambert, D. B., Blacklow, B., Henderson, M. J., et al. (2006). National estimates for mental health mutual support groups, self-help organizations, and consumer-operated services. Administration and Policy in Mental Health, 33(1), 92-103.

Hardiman, E. R., \& Segal, S. P. (2003). Community membership and social networks in mental health self-help agencies. Psychiatric Rehabilitation Journal, 27(1), 25-33.

Hatch, M. J., \& Cunliffe, A. L. (2006). Organization theory: Modern, symbolic, and postmodern perspectives. Oxford: Oxford University Press.

Heracleous, L. (2004). Boundaries in the study of organization. Human Relations, 57(1), 95-103.

Humphreys, K., \& Moos, R. H. (2007). Encouraging posttreatment self-help group involvement to reduce demand for continuing care services: Two-year clinical and utilization outcomes. Alcoholism: Clinical and Experimental Research, 31(1), 64-68.

Humphreys, K., Mavis, B., \& Stofflemayr, B. (1991). Factors predicting attendance at selfhelp groups after substance abuse treatment: Preliminary findings. Journal of Consulting and Clinical Psychology, 59(4), 591-593.

Humphreys, K. (1997). Clinicians' referral and matching of substance abuse patients to self-help groups after treatment. Psychiatric Services, 48(11), 1445-1449.

Humphreys, K. (1999). Professional interventions that facilitate 12-step self-help group involvement. Alcohol Research and Health, 23(2), 93-98.

Humphreys, K., Mavis, B. E., \& Stoffelmayr, B. E. (1994). Are twelve step programs appropriate for disenfranchised groups? Evidence from a study of posttreatment mutual help involvement. Prevention in Human Services, 11(1), 165-179.

Humphreys, K., Wing, S., McCarty, D., Chappel, J., Gallant, L., Haberle, B., et al. (2004). Selfhelp organizations for alcohol and drug problems: Toward evidence-based practice and policy. Journal of Substance Abuse Treatment, 26(3), 151-158.

Kessler, R. C., Zhao, S., Katz, S. J., Kouzis, A. C., Frank, R. G., Edlund, M., et al. (1999). Pastyear use of outpatient services for psychiatric problems in the national comorbidity survey. American Journal of Psychiatry, 156(1), 115-123. 
Kessler, R., Mickelson, K. D., \& Zhao, S. (1997). Patterns and correlates of self-help group membership in the United States. Social Policy, 27(3), 27-46.

Kurtz, L. F. (1985). Cooperation and rivalry between helping professionals and members of AA. Health \& Social Work, 10(2), 104-112.

Kurtz, L. F. (1997). Self-help and support groups: A handbook for practitioners. Thousand Oaks, CA: Sage.

Magura, S. (2007). The relationship between substance user treatment and 12-step fellowships: Current knowledge and research questions. Substance Use \& Misuse, 42(2-3), 343-360.

Magura, S., Laudet, A. B., Mahmood, D., Rosenblum, A., \& Knight, E. (2002). Adherence to medication regimens and participation in dual-focus self-help groups. Psychiatric Services, 53(3), 310-316.

Majer, J., Jason, L., North, C., Ferrari, J., Porter, N., Olson, B., et al. (2008). A longitudinal analysis of psychiatric severity upon outcomes among substance abusers residing in self-help settings. American Journal of Community Psychology, 42(1-2), 145-153.

Maton, K. I. (1988). Social support, organizational characteristics, psychological well-being, and group appraisal in three self-help group populations. American Journal of Community Psychology, 16(1), 53-77.

McLellan, A. T. (2008). Evolution in addiction treatment concepts and methods. In M. Galanter, H. D. Kleber, M. Galanter \& H. D. Kleber (Eds.), The American psychiatric publishing textbook of substance abuse treatment (4th ed., pp. 93-108). Arlington, VA: American Psychiatric Publishing, Inc.

Meissen, G. J., Mason, W. C., \& Gleason, D. F. (1991). Understanding the attitudes and intentions of future professionals towards self-help. American Journal of Community Psychology, 19(5), 699-714.

Meissen, G., Powell, T. J., Wituk, S. A., Girrens, K., \& Arteaga, S. (1999). Attitudes of AA contact persons toward group participation by persons with a mental illness. Psychiatric Services, SO(8), 1079-1081.

Meissen, G., Wituk, S., Warren, M., \& Shepherd, M. (2000). Self-help groups and managed health care: Obstacles and opportunities. International Journal of Self-Help and Self-Care, 1 (2), 201-210.

Meyer, J. W., \& Rowan, B. (1977). Institutionalized organizations: Formal structure as myth and ceremony. The American Journal of Sociology, 83(2), 340-363.

Meyer, J. W. (1986). Institutional and organizational rationalization in the mental health system. In W. R. Scott, \& B. L. Black (Eds.), The organization of mental health services. Beverly Hills, CA: Sage Publications.

Miller, N. S. (1994). Treating coexisiting psychiatric and addictive disorders: A practical guide. Center City, MN: Hazelden Educational Materials.

Moos, R. H. (2007). Theory-based processes that promote the remission of substance use disorders. Clinical Psychology Review, 27(5), 537.

Moos, R. H., \& Timko, C. (2008). Outcome research on 12-step and other self-help programs. In M. Galanter, H. D. Kleber, M. Galanter \& H. D. Kleber (Eds.), The American Psychiatric Publishing Textbook of Substance Abuse Treatment (4th ed., pp. 511-521). Arlington, VA: American Psychiatric Publishing, Inc.

Mowrer, O. H. (1984). The mental health professions and mutual-help program: Co-optation or collaboration. In A. Gartner, \& F. Riessman (Eds.), Self-help revolution (pp. 139-154). New York: Human Sciences Press Inc.

Murray, E., Burns, J., See-Tai, S., Lai, R., \& Nazareth, I. (2005). Interactive health communication applications for people with chronic disease. Cochrane Database of Systematic Reviews, 4, $1-70$.

Narrow, W. E., Regier, D. A., Rae, D. S., Manderscheid, R. W., \& Locke, B. Z. (1993). Use of services by persons with mental and addictive disorders: Findings from the national institute of mental health epidemiologic catchment area program. Archives of General Psychiatry, 50(2), 95-107. 
Norcross, J. C. (2006). Integrating self-help into psychotherapy: 16 practical suggestions. Professional Psychology-Research and Practice, 37(6), 683-693.

Nowinski, J., \& Baker, S. (1992). The twelve-step facilitation handbook: A systematic approach to early recovery from alcoholism and addiction. New York: Lexington Books.

Perron, B. E., Mowbray, O. P., Glass, J. E., Delva, J., Vaughn, M. G., \& Howard, M. O. (2009). Differences in service utilization and barriers among African Americans, Hispanics, and Caucasians with drug use disorders. Substance Abuse Treatment, Prevention, and Policy, 4, 1-10 (electronic).

Pistrang, N., Barker, C., \& Humphreys, K. (2008). Mutual help groups for mental health problems: A review of effectiveness studies. American Journal of Community Psychology, 42(1), 110-121.

Powell, T., \& Perron, B. E. (2010). Self-help groups and mental Health/Substance use agencies: The benefits of organizational exchange. Substance Use \& Misuse, 45

Powell, T. J. (1990). Self-help, professional help, and informal help: Competing or complementary systems? In T. J. Powell (Ed.), Working with self-help (pp. 31-49). Silver Spring, MD: National Association of Social Workers.

Powell, T. J., Hill, E. M., Warner, L., Yeaton, W., \& Silk, K. R. (2000). Encouraging people with mood disorders to attend a self-help group. Journal of Applied Social Psychology, 30(11), 2270-2288.

Powell, T. J., Yeaton, W., Hill, E. M., \& Silk, K. R. (2001). Predictors of psychosocial outcomes for patients with mood disorders: The effects of self-help group participation. Psychiatric Rehabilitation Journal, 25(1), 3-11.

Project MATCH Research Group: Allen, J., Anton, R. F., Babor, T. F., Carbonari, J., Carroll, K. M., Connors, G. J., et al. (1998). Matching alcoholism treatments to client heterogeneity: Project Match three-year drinking outcomes. Alcoholism-Clinical and Experimental Research, 22(6), 1300-1311.

Raven, B. H. (1988). Social power and compliance in health care. In S. Maes, C. D. Spielberger, P. B. Defares \& I. G. Sarason (Eds.), Topics in health psychology (pp. 229-244). New York: Wiley.

Raven, B., Schwarzwald, J., \& Koslowsky, M. (1998). Conceptualizing and measuring a Power/Interaction model of interpersonal influence. Journal of Applied Social Psychology, 28(4), 307-332.

Ries, R. K., Galanter, M., \& Tonigan, J. S. (2008). Twelve-step facilitation. In M. Galanter, H. D. Kleber, M. Galanter \& H. D. Kleber (Eds.), The American psychiatric publishing textbook of substance abuse treatment (4th ed., pp. 373-386). Arlington, VA US: American Psychiatric Publishing, Inc.

Riessman, F. (1965). The helper-therapy principle. Social Work, 10(2), 27-32.

Riessman, F., David. (1995). Redefining self-help. San Francisco: Jossey Bass.

Roberts, L. J., Salem, D., Rappaport, J., Toro, P. A., Luke, D. A., \& Seidman, E. (1999). Giving and receiving help: Interpersonal transactions in mutual-help meetings and psychosocial adjustment of members. American Journal of Community Psychology, 27(6), 841-868.

Sagarin, E. (1969). Odd man in: Societies of deviants in America. New York: Quadrangle.

Salem, D. A., Reischl, T. M., Gallacher, F., \& Randall, K. W. (2000). The role of referent and expert power in mutual help. American Journal of Community Psychology, 28(3), 303-324.

Salem, D., Reischl, T., \& Randall, K. (2008). The effect of professional partnership on the development of a mutual-help organization. American Journal of Community Psychology, 42(1-2), 179-191.

Salzer, M. S., Rappaport, J., \& Segre, L. (2001). Mental health professionals' support of self-help groups. Journal of Community \& Applied Social Psychology, 11(1), 1-10.

Salzer, M. S., Rappaport, J., \& Segre, L. (1999). Professional appraisal of professionally led and self-help groups. American Journal of Orthopsychiatry, 69(4), 536-540.

Schacter, S. (1959). The psychology of affiliation. Stanford, CA: Stanford University Press. 
Schmid, H. (2004). Organization-environment relationships: Theory for management practice in human service organizations. Administration-in-Social-Work, 28(1), 97-113.

Schubert, M. A., \& Borkman, T. J. (1991). An organizational typology for self-help groups. American Journal of Community Psychology, 19(5), 769-787.

Scott, W. R. (2005). Institutional theory: Contributing to a theoretical research program. In K. G. Smith, \& M. A. Hitt (Eds.), Great minds of management: The process of theory development (2nd ed., pp. 460-484). New York: Oxford University Press.

Scott, W. R. (2003). Organizations: Rational, natural, and open systems. Upper Saddle River, NJ: Prentice Hall.

Scott, W. R. (2001). Institutions and organizations (2nd ed.). Thousand Oaks, CA: Sage.

Seligman, M. (1995). The effectiveness of psychotherapy: The Consumer Reports study. American Psychologist, 50(12), 965-974.

Shepherd, M. D., Schoenberg, M., Slavich, S., Wituk, S., Warren, M., \& Meissen, G. (1999). Continuum of professional involvement in self-help groups. Journal of Community Psychology, 27(1), 39-53.

Timko, C., \& Debenedetti, A. (2007). A randomized controlled trial of intensive referral to 12-step self-help groups: One-year outcomes. Drug \& Alcohol Dependence, 90(2-3), 270-279.

Timko, C., Debenedetti, A., \& Billow, R. (2006). Intensive referral to 12-step self-help groups and 6-month substance use disorder outcomes. Addiction, 101(5), 678-688.

Toro, P., Zimmerman, M., Seidman, E., Reischl, T., Rappaport, J., Luke, D., et al. (1988). Professionals in mutual help groups: Impact on social climate and members' behaviour. Journal of Consulting and Clinical Psychology, 56(4), 631-632.

United States Public Health Service (USPHS), Office of the Surgeon General (OSG), Center for Mental Health Services (CMHS), \& National Institute of Mental Health (NIMH.). (2000). Mental health A Report of the Surgeon General. Washington, DC: Department of Health and Human Services.

Wang P. S., Lane, M., Olfson, M., Pincus H., A., Wells K., B., \& Kessler R., C. (2005). Twelve-month use of mental health services in the United States: Results from the National Comorbidity Survey Replication. Archives of General Psychiatry, 62(6), 629-640.

Wang, P. S., Berglund, P., Olfson, M., Pincus, H. A., Wells, K. B., \& Kessler, R. C. (2005). Failure and delay in initial treatment contact after first onset of mental disorders in the national comorbidity survey replication. Archives of General Psychiatry, 62(6), 603-613.

Wang, P. S., Berglund, P., \& Kessler, R. C. (2000). Recent care of common mental disorders in the United States: Prevalence and conformance with evidence-based recommendations. Journal of General Internal Medicine, 15(5), 284-292.

Warner, L., Silk, K., Yeaton, W. H., Bargal, D., Janssen, J., \& Hill, E. M. (1994). Psychiatrists' and patients' views on drug information and medication compliance. Hospital and Community Psychiatry, 45(12), 1235-1237.

Watkins, P. L., \& Clum, G. A. (2008). Handbook of self-help therapies. New York: Routledge.

White, W., \& Kurtz, E. (2005). The varieties of recovery experience: A primer for addiction treatment professionals and recovery advocates. International Journal of Self Help and Self Care, $3(1), 21-61$.

White, W. L. (1998). Slaying the dragon: The history of addiction treatment and recovery in America. Bloomington, IL: Chestnut Health Systems/Lighthouse Institute.

World Health Organization (WHO), (2001). The world health report 2001 - mental health: New understanding, new hope. Retrieved online January 23, 2009 from http://www.who. int/whr/2001/en/.

Wilson, J. (1995a). How to work with self-help groups: Guidelines for professionals. Hants: Arena/Ashgate Publishing.

Wilson, J. (1995b). Two worlds: Self-help groups and professionals. London: Venture Press.

Wituk, S., Ealey, S., Brown, L., Shepherd, M., \& Meissen, G. (2005). Assessing the needs and strengths of self-help groups: Opportunities to meet health care needs. International Journal of Self Help \& Self Care, 3(1-2), 103-116. 
Wituk, S., Shepherd, M. D., Slavich, S., Warren, M. L., \& Meissen, G. (2000). A topography of self-help groups: An empirical analysis. Social Work, 45(2), 157-165.

Wituk, S. A., Tiemeyer, S., Commer, A., Warren, M., \& Meissen, G. (2003). Starting self-help groups: Empowering roles for social workers. Social Work with Groups, 26(1), 83-92. 